\title{
EL DERECHO A UN MEDIOAMBIENTE SANO EN EL SISTEMA INTERAMERICANO DE DERECHOS HUMANOS
}

\author{
The right to a healthy environment in the inter-american \\ human rights system
}

\begin{abstract}
Isaac Marcelo Basaure Miranda
Abogado por la Universidad Nacional de Lomas de Zamora (Argentina)

Diplomado en Derechos Económicos, Sociales y Culturales por la Universidad Nacional de la Patagonia San Juan Bosco
\end{abstract}

http://dx.doi.org/10.18543/ed-69(1)-2021pp187-209

Recibido: 25.03 .2021

Aceptado: 18.06 .2021

\section{Resumen}

El presente artículo tiene como objetivo abordar las principales normas y jurisprudencia contenciosa y consultiva del Sistema Interamericano de Derechos Humanos, relativas a la protección al derecho de un medioambiente sano, a la luz de la novedad que supone la Opinión Consultiva (OC-23/17), primera opinión emitida por la Corte Interamericana de Derechos Humanos sobre medioambiente, con el fin de identificar las obligaciones estatales que la legislación internacional le ha impuesto a los Estados americanos en la materia.

\section{Palabras clave}

Sistema Interamericano; Derechos Humanos; Derecho Ambiental; Corte Interamericana de Derechos Humanos; Comisión Interamericana de Derechos Humanos.

\section{Abstract}

The objective of this paper is to analyze the main litigation and advisory laws and jurisprudence of the Inter-American Human Rights System, regarding the protection 
of the right to a healthy environment, in the light of the first Advisory Opinion (OC23/17) issued by the Inter-American Court of Human Rights about the environment, in order to identify the scope and state limits that international law has imposed on the American States in this area.

\section{Keywords}

Inter-American System; Human Rights; Environmental Law; Inter-American Court of Human Rights; Inter-American Commission on Human Rights. 


\begin{abstract}
Sumario: I. INTRODUCCiÓN. II. ANTECEDENTES Y RECEPCIÓN DEL DERECHO A UN MEDIOAMBIENTE SANO EN EL SISTEMA INTERAMERICANO DE Derechos Humanos. III. Alcance y LÍMites de las obligaciones AMBIENTALES IMPUESTAS A LOS ESTADOS AMERICANOS EN LA OPINIÓN Consultiva OC-23/17. 1. Obligaciones de los Estados en materia de protección ambiental. 2. El deber de debida diligencia. IV. LA PROTECCIÓN AMBIENTAL EN LA JURISPRUDENCIA CONTENCIOSA RECIENTE de la Corte Interamericana de Derechos Humanos. V. ConcluSIONES. BIBLIOGRAFÍA.
\end{abstract}

\title{
I. INTRODUCCIÓN
}

El 15 de noviembre de 2017 la Corte Interamericana de Derechos Humanos (en adelante Corte IDH), a los fines de dar cumplimiento a la solicitud efectuada por la República de Colombia, emitió la Opinión Consultiva OC$23 / 17^{1}$ (en adelante OC-23/17) sobre medioambiente y derechos humanos, en la cual el tribunal se expidió por primera vez acerca del derecho a gozar de un medioambiente sano, reconociéndolo como un derecho en sí mismo; además de admitir la relación indisoluble que existe entre la tutela jurídica ambiental y la efectiva realización de los derechos humanos ${ }^{2}$. En este sentido, la Corte IDH ha determinado en el precitado documento consultivo, el carácter indivisible e interdependiente que rige el vínculo entre el medioambiente, el desarrollo sostenible y los derechos humanos.

Teniendo en cuenta lo anterior, se puede deducir que garantizar un ambiente ecológico saludable a la población, implica un presupuesto elemental para que los demás derechos humanos puedan desarrollarse y ejercerse plenamente: «Todos los derechos humanos son vulnerables a la degradación ambiental, en el sentido de que el pleno disfrute de todos los derechos humanos depende de un medio propicio». (Corte Interamericana de Derechos Humanos: 2017, 25). Por ello, es al Estado a quien le corresponde asegurar las condiciones necesarias para que el daño ambiental no vulnere los derechos humanos.

${ }^{1}$ Corte Interamericana de Derechos Humanos. Opinión Consultiva OC-23/17. Serie A, No. 23. (15 de noviembre de 2017). Recuperado de http://www.corteidh.or.cr/docs/ opiniones/seriea_23_esp.pdf

${ }^{2}$ Ibid., pp. $\overline{21}-\overline{22}$, considerando 47: «Esta Corte ha reconocido la existencia de una relación innegable entre la protección del medio ambiente y la realización de otros derechos humanos, en tanto la degradación ambiental y los efectos adversos del cambio climático afectan el goce efectivo de los derechos humanos»». 
Así las cosas, la mentada opinión consultiva adquiere importancia, no solo por establecer cuáles son las obligaciones ambientales que los Estados deben cumplir, sino porque también determina sus alcances. Considerando que la OC-23/17 supone el primer análisis específico que la Corte IDH efectúa sobre la problemática del medioambiente, el presente trabajo se propone como objetivo examinar los principales estándares de interpretación contenidos en ella en materia ambiental, en general, y en lo que respecta al derecho a un medioambiente sano, en particular.

Por otro lado, a la luz de las novedades contenidas en la OC-23/17, también se estudiará cómo ha sido receptado el derecho a un medioambiente sano en el Sistema Interamericano de Derechos Humanos (en adelante SIDH), con el fin de identificar los alcances y límites estatales que la Convención Americana sobre Derechos Humanos (en adelante CADH), y otros pactos internacionales, le han impuesto a los Estados americanos en la materia.

\section{ANTECEDENTES Y RECEPCIÓN DEL DERECHO A UN MEDIOAMBIENTE SANO EN EL SISTEMA INTERAMERICANO DE DERECHOS HUMANOS}

El derecho a gozar de un medioambiente sano supone tener en cuenta, al menos, dos dimensiones: la primera de ellas se refiere a uno de los bienes jurídicos que protege, es decir, el medioambiente. Este puede ser definido como:

«... la manifestación actual de las relaciones que se dan entre los diversos ecosistemas - tanto los existentes en los ámbitos urbanos como naturales - que produciendo un conjunto de condiciones, inciden de forma determinante en las posibilidades de desarrollo integral de los seres humanos». (Bermúdez Soto 2007, 55-56).

Ahora bien, la otra dimensión —el segundo objeto de protección jurídica-, es, evidentemente, la persona humana, ya que esta, en tanto sujeto de derecho, es capaz de ser titular de derechos y obligaciones, y es ella quien debe tener garantizado el acceso a un ambiente saludable. El ser humano convive e interactúa con el ecosistema que lo circunda, siendo capaz de alterarlo con sus acciones u omisiones; ejemplo de ello son los grandes desastres ambientales que se han sucedido en la Edad Contemporánea, desde Chernóbil (1986) hasta Fukushima (2011), ambas catástrofes nucleares han traído aparejadas consecuencias nocivas y degradantes para el medioambiente. En la misma línea, pueden mencionarse los bombardeos atómicos de Hiroshima y Nagasaki (1945), y su consecuente cúmulo de enfermedades provocadas por la radiación. 
En virtud de lo expuesto, se entiende que el derecho a disfrutar de un medioambiente sano resulta inseparable de la naturaleza humana, pues hace posible una vida digna y plena, es, en definitiva, parte de los derechos humanos. La interrelación e interdependencia constante entre el hombre y el ambiente, es lo que ha propiciado su regulación normativa. Como consecuencia de ello, la doctrina suele definir al derecho a tener un medioambiente sano como:

«... un derecho de titularidad individual pero de acción colectiva, es decir que le pertenece a cada ser humano, quien puede protegerlo por su naturaleza difusa mediante la acción judicial que corresponda» (Cárdenas Hernández 2011, 212-220).

Ello es así por dos factores: primero, porque es el ser humano «quien lo disfruta o lo padece, y segundo porque los derechos humanos son para los individuos, cuyos destinatarios y titulares son siempre las personas, los seres humanos, y no un colectivo o comunidad difusa». (Cárdenas Hernández 2011, 212-220).

Desde una perspectiva histórica, el primer antecedente notable que ha contribuido a consolidar la tutela del ambiente a nivel internacional es la Conferencia de las Naciones Unidas sobre el Medio Humano, celebrada en la ciudad de Estocolmo, Suecia, en 1972. La misma, en su art. 2, proclamó que:

«La protección y mejoramiento del medio ambiente humano es una cuestión fundamental que afecta al bienestar de los pueblos y al desarrollo económico del mundo entero, un deseo urgente de los pueblos de todo el mundo y un deber de todos los gobiernos». (Conferencia de las Naciones Unidas sobre Medio Humano 1972).

Como se observa, con esta declaración, la comunidad internacional iniciaba el reconocimiento expreso del derecho de los seres humanos a contar con un ambiente sano, además de imponerles a los Estados el compromiso de asegurarlo.

Algunos años más tarde, y en consonancia con lo dispuesto en la cumbre de Estocolmo, se rubricó en el ámbito interamericano el Protocolo Adicional a la Convención Americana sobre Derechos Humanos en materia de Derechos Económicos, Sociales y Culturales (1988), también conocido como Protocolo de San Salvador, el cual consagra con claridad, en su art. 11.1, el derecho a un medioambiente sano: «Toda persona tiene derecho a vivir en un medio ambiente sano y a contar con servicios públicos básicos». (Protocolo Adicional a la Convención Americana sobre Derechos Humanos en materia de Derechos Económicos, Sociales y Culturales 1988). Otro aspecto sustancial del protocolo, es el atinente a la obligación que se le impone a los Estados relativa a garantizar un ambiente sano, tal es lo que surge de su art. 11.2: «Los Estados partes promoverán la protección, preservación y mejoramiento 
del medio ambiente». (Protocolo Adicional a la Convención Americana sobre Derechos Humanos en materia de Derechos Económicos, Sociales y Culturales 1988). Aquí es oportuno mencionar que hasta la aparición de la OC-23/17, las precitadas disposiciones del Protocolo de San Salvador constituían, junto con el art. 19.13 de la Declaración Americana sobre los Derechos de los Pueblos Indígenas (2016), las únicas referencias normativas directas en materia de regulación ambiental dentro del SIDH.

Continuando con los instrumentos internacionales que han receptado la defensa del ambiente, debemos aludir a la Declaración de Río sobre el Medio Ambiente y el Desarrollo, dictada por la ONU en 1992, donde en el principio $\mathrm{N}^{\mathrm{o}}$ 1, se reafirma el derecho a un medioambiente sano: «Los seres humanos constituyen el centro de las preocupaciones relacionadas con el desarrollo sostenible. Tienen derecho a una vida saludable y productiva en armonía con la naturaleza». (Declaración de Río sobre el Medio Ambiente y el Desarrollo 1992). Por otra parte, en el principio $N^{o} 11$, nuevamente se impone a los Estados ejercer acciones positivas en resguardo del medioambiente: «Los Estados deberán promulgar leyes eficaces sobre el medio ambiente». (Declaración de Río sobre el Medio Ambiente y el Desarrollo 1992).

Posteriormente, los principios consagrados en las cumbres de Estocolmo y Río de Janeiro, fueron confirmados por la Tercera Cumbre Mundial de las Naciones Unidas sobre Ambiente y Desarrollo de Johannesburgo, realizada en el año 2002, agregando nuevos objetivos, como la erradicación de la pobreza y el reemplazo del sistema de producción y de consumo por otro que se sustente en el respeto hacia los recursos naturales y el desarrollo sostenible.

Por lo desarrollado hasta aquí, podemos colegir que en los documentos internacionales previamente reseñados, se vislumbra una ostensible intención de categorizar al derecho a gozar de un medioambiente sano como un derecho humano. En efecto, sería erróneo clasificarlo de otro modo, toda vez que «es un derecho inherente a la dignidad humana, de forma que sin un medio ambiente adecuado una persona no puede vivir dignamente». (De Luis García 2018, 550-569). Es precisamente esta característica lo que hace que el derecho a un medioambiente sano se encuentre inexorablemente ligado a otros derechos de igual importancia, como lo son: el derecho a la vida, el derecho a la integridad personal y el derecho a la salud.

En este orden de ideas, es cuando adquiere relevancia la $\mathrm{CADH}$, máximo tratado sobre derechos humanos en el continente americano. La relación

3 Artículo 19.1 de la Declaración Americana sobre los Derechos de los Pueblos Indígenas (2016): «Los pueblos indígenas tienen derecho a vivir en armonía con la naturaleza y a un ambiente sano, seguro y sustentable, condiciones esenciales para el pleno goce del derecho a la vida, a su espiritualidad, cosmovisión y al bienestar colectivo». 
intrínseca que se suscita entre el derecho a un medioambiente sano y el resto de las garantías convencionales, ha ocasionado que la Corte IDH, en su calidad de intérprete de la CADH $\left(\right.$ art. $\left.33^{4}\right)$ a solicitud de Colombia, haya delimitado en la OC-23/17, la responsabilidad estatal de los Estados en lo referente a la temática ambiental.

\section{ALCANCE Y LÍMITES DE LAS OBLIGACIONES AMBIENTALES IMPUESTAS A LOS ESTADOS AMERICANOS EN LA OPINIÓN CONSULTIVA OC-23/17}

El 14 de marzo de 2016 la República de Colombia, ejerciendo el derecho que le confiere el art. $64^{5}$ de la $\mathrm{CADH}$, solicitó a la Corte IDH que esclareciera, mediante el dictamen de una opinión consultiva, cuáles son las obligaciones estatales que los Estados signatarios de la CADH deben observar en materia de protección ambiental, y cuál es el ámbito de aplicación de las mismas. De esta forma, la Corte IDH, cada vez que dicta una opinión consultiva, está ejerciendo su función consultiva, la misma se halla contemplada en el art. $2^{6}$ de su estatuto.

El día 15 de noviembre de 2017, La Corte IDH cumplió la exigencia de Colombia al emitir la OC-23/17, materializando así, la primera ocasión en que el alto tribunal se manifiesta, en extenso, sobre la problemática ambiental. De la OC-23/17 se pueden extraer una serie de valiosos estándares interpretativos para la región: A) el primero de ellos es que la Corte IDH reconoce la interrelación innegable que existe entre el medioambiente y los derechos humanos, es decir, no son cuestiones que, jurídicamente, deban valorarse de forma independiente, como compartimentos estancos: «la degradación

${ }^{4}$ Artículo 33 de la Convención Americana sobre Derechos Humanos: «Son competentes para conocer de los asuntos relacionados con el cumplimiento de los compromisos contraídos por los Estados Partes en esta Convención: a) la Comisión Interamericana de Derechos Humanos, llamada en adelante la Comisión, y b) la Corte Interamericana de Derechos Humanos, llamada en adelante la Corte».

${ }_{5}$ Artículo 64 de la Convención Americana sobre Derechos Humanos: «1. Los Estados miembros de la Organización podrán consultar a la Corte acerca de la interpretación de esta Convención o de otros tratados concernientes a la protección de los derechos humanos en los Estados americanos. Asimismo, podrán consultarla, en lo que les compete, los órganos enumerados en el capítulo X de la Carta de la Organización de los Estados Americanos, reformada por el Protocolo de Buenos Aires. 2. La Corte, a solicitud de un Estado miembro de la Organización, podrá darle opiniones acerca de la compatibilidad entre cualquiera de sus leyes internas y los mencionados instrumentos internacionales».

${ }^{6}$ Artículo 2. del Estatuto de la Corte Interamericana de Derechos Humanos: «La Corte ejerce función jurisdiccional y consultiva: 1 . Su función jurisdiccional se rige por las disposiciones de los artículos 61, 62 y 63 de la Convención. 2. Su función consultiva se rige por las disposiciones del artículo 64 de la Convención». 
ambiental y los efectos adversos del cambio climático afectan el goce efectivo de los derechos humanos». (Corte Interamericana de Derechos Humanos 2017, 21-22). Sobre esta base se entiende que sin un medioambiente de calidad no es factible el desarrollo óptimo de los derechos humanos.

B) El derecho a un medioambiente sano no solo se encuentra receptado expresamente en el art. 11 del Protocolo de San Salvador, sino que también debe considerárselo incluido en el art. $26^{7}$ de la $\mathrm{CADH}$, en tanto es un elemento clave para fomentar el desarrollo progresivo y sustentable de la sociedad.

C) Enumeración y clasificación de los derechos humanos más vulnerables al daño ambiental: el derecho a la vida, el derecho a la integridad personal, el derecho a la salud, el derecho a la vivienda, el derecho a la propiedad, el derecho a la alimentación, el derecho al agua, el derecho a no ser desplazado forzadamente, y el derecho a participar en la vida cultural; a este conjunto de derechos se los denomina «sustantivos», toda vez que cualquier impacto ambiental los afecta de modo directo. El segundo grupo de derechos, son los denominados «derechos de procedimiento», ya que su ejercicio contribuye al progreso de políticas ambientales, entre ellos se encuentran: el derecho a la libertad de expresión, de asociación, de acceso a la información, el derecho a acceder a un recurso efectivo, y el derecho a la participación en la toma de decisiones.

D) Contenido y alcance del derecho a un medioambiente sano: la Corte IDH lo ha entendido como un derecho de doble alcance, es decir, por un lado tiene una extensión universal y colectiva, orientada a proteger las generaciones presentes y futuras; y por el otro, presenta un interés individual, debido a que su violación supone consecuencias inmediatas para las personas. Así, pueden verse socavados otros derechos, como el derecho a la vida o a la salud. Paralelamente, el tribunal reconoce que el objeto de protección del derecho a un medioambiente sano, no puede verse reducido al ser humano, sino que, por el contrario, este es extensivo a toda la naturaleza en general, por ello: los océanos, glaciares, bosques, la flora, la fauna, y demás recursos naturales, deben considerarse como intereses jurídicos en sí mismos en el entendido de que:

«Se trata de proteger la naturaleza y el medio ambiente no solamente por su conexidad con una utilidad para el ser humano o por los efectos que su degradación podría causar en otros derechos de las personas (...) sino

7 Artículo 26 de la Convención Americana sobre Derechos Humanos: «Los Estados Partes se comprometen a adoptar providencias, tanto a nivel interno como mediante la cooperación internacional, especialmente económica y técnica, para lograr progresivamente la plena efectividad de los derechos que se derivan de las normas económicas, sociales y sobre educación, ciencia y cultura, contenidas en la Carta de la Organización de los Estados Americanos, reformada por el Protocolo de Buenos Aires, en la medida de los recursos disponibles, por vía legislativa u otros medios apropiados». 
por su importancia para los demás organismos vivos con quienes se comparte el planeta, también merecedores de protección en sí mismos». (Corte Interamericana de Derechos Humanos 2017, 28-29).

Nótese que la posición de la Corte IDH, en este extremo, no deja de ser novedosa, puesto que adopta el paradigma del biocentrismo jurídico —en contraposición al antropocentrismo-, admitiendo que la naturaleza y demás sistemas naturales, son, en sí mismos, sujetos de derechos.

Como se observa, la Corte IDH manifiesta cierta tendencia al ecologismo, el cual sostiene que: «una existencia sustentable y satisfactoria implica cambios radicales en la relación con el mundo natural no humano y en las formas de vida social y política». (Dobson 1997, 22-23). Sin dudas, entre dichas modificaciones, se encuentra la de preservar los ecosistemas y la biodiversidad, con miras a garantizar un ambiente sano, tanto para el hombre, como para otras formas de vida.

\section{Obligaciones de los Estados en materia de protección ambiental}

El primer punto al que hay que hacer referencia cuando se analizan las obligaciones de los Estados en materia de protección ambiental, es el del ámbito de aplicación y su correspondiente jurisdicción. La Corte IDH, en la OC-23/17, consideró que:

«... las obligaciones de los Estados Partes no están restringidas al espacio geográfico correspondiente a su territorio, sino que abarca aquellas situaciones donde, aún fuera del territorio de un Estado, una persona se encuentre bajo su jurisdicción $»^{8}$. (Corte Interamericana de Derechos Humanos 2017, 35).

De modo que el Estado no solo es responsable por los actos que se produzcan dentro de su territorio, sino que también responde por las conductas extraterritoriales cometidas bajo su jurisdicción. Esto se vincula directamente con los llamados «daños ambientales transfronterizos», es decir, aquellos que lesionan derechos humanos de personas que se hallen fuera del territorio del Estado en cuestión, pero dentro de su jurisdicción o autoridad. Conforme surge del art. $1.1^{9}$ de la $\mathrm{CADH}$, los Estados partes deben cumplir

${ }^{8}$ Corte Interamericana de Derechos Humanos. Opinión Consultiva OC-23/17. Serie A, No. 23. (15 de noviembre de 2017), p. 35.

9 Artículo 1.1 de la Convención Americana sobre Derechos Humanos: «Los Estados Partes en esta Convención se comprometen a respetar los derechos y libertades reconocidos en ella y a garantizar su libre y pleno ejercicio a toda persona que esté sujeta a su jurisdicción, sin discriminación alguna por motivos de raza, color, sexo, idioma, religión, opiniones políticas o de cualquier otra índole, origen nacional o social, posición económica, nacimiento o cualquier otra condición social». 
con la exigencia de respetar los derechos contenidos en la convención, además de garantizar su efectivo ejercicio. En concordancia con ello, la Corte IDH desarrolla en la OC-23/17, dos grupos de obligaciones estatales: uno basado en el respeto, y otro fundado en el deber de garantía.

Dentro del primero ubicamos a las obligaciones de abstención, donde se limita el accionar del poder estatal, a fin de evitar el ejercicio de políticas que conduzcan a ocasionar daños ambientales. En este orden, identificamos dos grandes restricciones, la primera de ellas es la obligación de abstenerse de ejecutar «cualquier práctica o actividad que deniegue o restrinja el acceso, en condiciones de igualdad, a los requisitos para una vida digna, como lo son, el agua y la alimentación adecuada, entre otros». (Corte Interamericana de Derechos Humanos 2017, 50).

Aquí es necesario destacar que la Corte IDH ubica como derechos vulnerables a la degradación ambiental, no solo al derecho a la vida humana, sana y digna, sino que dicha tutela es susceptible de aplicarse, también, a otros bienes jurídicos, como el derecho al agua y a la alimentación, entre otros. De lo citado se desprende, entonces, que para activar los mecanismos de protección ambiental, no resulta una conditio sine qua non la exclusiva vulneración del derecho a la vida, a la integridad personal o a la salud, sino que basta una amenaza estatal, cierta y comprobable, que eventualmente pueda vulnerar el agua, los alimentos o la propiedad, en el sentido de que poseen una protección individual, siendo esta enumeración meramente enunciativa y no taxativa.

La segunda restricción hace referencia a la prohibición de «contaminar ilícitamente el medio ambiente de forma que se afecte las condiciones que permiten la vida digna de las personas» (Corte Interamericana de Derechos Humanos 2017, 50). Dentro de este supuesto, pueden englobarse las acciones nocivas que llevan adelante las empresas estatales, las cuales derivan de diferentes tipos de contaminación: polución, irradiación de gases de efecto invernadero, basurales a cielo abierto, derrames de petróleo, vertidos y emisiones de sustancias tóxicas sobre los ríos y mares, etc.

El segundo grupo de obligaciones estatales está integrado por deberes convencionales de garantía; de modo que los Estados deben adoptar «todas las medidas apropiadas para proteger y preservar los derechos a la vida y a la integridad». (Corte Interamericana de Derechos Humanos 2017, 50). Dicho deber de garantía incluye tanto la esfera pública y estatal, en sus diversas interrelaciones, como también aquellas que se producen en el ámbito privado; es decir, los Estados tienen la obligación de evitar que terceros causen lesiones a los derechos ambientales, siendo este mandato de carácter preventivo.

Según la Corte IDH, el deber de garantía abarca: «todas aquellas medidas de carácter jurídico, político, administrativo y cultural que promuevan la salvaguarda de los derechos humanos». (Corte Interamericana de Derechos Humanos 2017, 50). Sin embargo, debemos preguntarnos qué sucede cuando se ha 
producido un daño ambiental como consecuencia de la acción de un agente no estatal, es decir, de un tercero; ¿en qué casos la responsabilidad internacional de los Estados queda comprometida, ante un atentado contra el medioambiente cometido por un particular? Según la Corte IDH, esta se patentiza con la comprobación de omisiones estatales, tales como: «falta de regulación, supervisión o fiscalización de las actividades de estos terceros que causen un daño al medio ambiente». (Corte Interamericana de Derechos Humanos 2017, 51).

Simultáneamente, las precitadas hipótesis deben ir acompañadas de dos circunstancias: a) al momento de suscitarse la violación al medioambiente, las autoridades estatales

«... sabían o debían saber de la existencia de una situación de riesgo real e inmediato para la vida de un individuo o grupo de individuos determinados, y no tomaron las medidas necesarias dentro del ámbito de sus atribuciones». (Corte Interamericana de Derechos Humanos 2017, 51).

b) el segundo presupuesto que plasma la responsabilidad estatal, es la comprobación del nexo causal. Según la Corte IDH, debe existir «una relación de causalidad entre la afectación a la vida o la integridad y el daño significativo causado al medio ambiente». (Corte Interamericana de Derechos Humanos 2017, 51).

De lo anterior se concluye que las obligaciones estatales, respecto al accionar de los particulares, no son ilimitadas, toda vez que para atribuirle responsabilidad al Estado, es necesario constatar la existencia de los requisitos previamente desarrollados en la coyuntura del caso concreto.

\section{El deber de debida diligencia}

La noción de debida diligencia, en materia de derecho internacional público, puede ser entendida como

«... la obligación de prevenir, investigar y sancionar el hecho violatorio de los derechos humanos, en los supuestos en los que el Estado incumple estas obligaciones por omisión de sus órganos, o en casos de cumplimiento deficiente». (García Elorrio 2011, 1-30).

Por lo demás, el propio art. $2^{10}$ de la CADH consagra tácitamente a la debida diligencia, cuando impone a los Estados miembros la realización de

${ }_{10}$ Artículo 2 de la Convención Americana sobre Derechos Humanos: «Si el ejercicio de los derechos y libertades mencionados en el artículo 1 no estuviere ya garantizado por disposiciones legislativas o de otro carácter, los Estados Partes se comprometen a adoptar, con arreglo a sus procedimientos constitucionales y a las disposiciones de esta Convención, las medidas legislativas o de otro carácter que fueren necesarias para hacer efectivos tales derechos y libertades»». 
medidas apropiadas para hacer efectivas las garantías y derechos incluidos en ella.

En la OC-23/17, la Corte IDH le otorga un rol clave al cumplimiento de la debida diligencia, entendiéndola como un deber sobre el cual «reposan la mayoría de las obligaciones en materia ambiental». (Corte Interamericana de Derechos Humanos 2017, 53). Es conveniente distinguir aquí, que la naturaleza jurídica de la debida diligencia no es de resultado, sino que se la concibe como una obligación de comportamiento. Ello es así, porque no se exige el logro de un objetivo en particular, sino la adecuación de una conducta a los fines de lograr la efectividad de los derechos.

El concepto de debida diligencia, en materia de medioambiente, es sustancial, porque abarca una multiplicidad de obligaciones específicas, cuyo ámbito de aplicación se extiende tanto a los daños acontecidos dentro del territorio estatal, como a los daños que traspasen sus fronteras; entre ellas, podemos citar: a) las obligaciones de prevención, b) la obligación de aplicar el principio de precaución, c) la obligación de cooperación, y d) las obligaciones de procedimiento.

A) Obligaciones de prevención: se basan en el principio de prevención, según el cual los Estados deben desplegar acciones tendientes a evitar que sus actividades dañen el medioambiente de otro Estado o de áreas donde este no ejerza su jurisdicción. En este punto cabe preguntarse cuándo surge la obligación estatal de prevenir, es decir, ¿a qué daños se circunscribe? La Corte IDH ha determinado que los daños a evitar son aquellos de carácter significativo, entendiendo por estos: «cualquier daño al medio ambiente que pueda conllevar una violación de los derechos a la vida o a la integridad personal, conforme al contenido y alcance de dichos derechos». (Corte Interamericana de Derechos Humanos 2017, 58).

La primera de las obligaciones de prevención, es el deber de regulación: alude a que los Estados deben adoptar todas las medidas necesarias para regular aquellas actividades que, eventualmente, puedan ocasionar un daño ambiental significativo; siendo para ello fundamental la imposición de estudios de impacto ambiental, a los fines de determinar el nivel de riesgo de cada actividad. Con dicha obligación, se busca disminuir las amenazas a los derechos a la vida y a la integridad personal.

La segunda obligación de prevención es la de supervisar y fiscalizar: hace referencia a que los Estados deben desarrollar mecanismos de control para supervisar y fiscalizar las actividades que, potencialmente, puedan contribuir a ocasionar un daño significativo al medioambiente. En este sentido, se debe inspeccionar tanto a las entidades públicas, como privadas, que realicen tales tareas de riesgo. Asimismo, es esencial que los Estados lleven a cabo diligencias tales como: rendición de cuentas, medidas preventivas y procedimientos de investigación, sanción y reparación, cuando corresponda. 
La tercera obligación de prevención es la de requerir y aprobar estudios de impacto ambiental: antes de la sanción de la OC-23/17, la Corte IDH había expresado su posición respecto a que los estudios de impacto ambiental solo eran obligatorios en actividades realizadas dentro del territorio de comunidades nativas, sin embargo, tras la publicación de la opinión consultiva, tal obligación se ha hecho extensiva a cualquier actividad que pueda ocasionar un daño significativo al medioambiente.

De modo que siempre que se acredite, a través de un examen preeliminar, que una labor pueda ocasionar un daño ambiental significativo, los Estados deben cumplir la obligación de realizar un estudio de impacto ambiental. Vale aclarar que dicha observancia es obligatoria e ineludible, tanto para los agentes estatales como para las personas privadas.

El análisis de impacto ambiental que tanto los Estados, como los terceros ajenos a este, deben poner en práctica, tiene que reunir las siguientes exigencias: debe llevarse a cabo y concluirse antes de iniciar la actividad; el estudio tiene que ser implementado por entidades calificadas e independientes, bajo la supervisión del Estado; abarcar el impacto acumulado, en el sentido de que debe estudiar las eventuales consecuencias de los proyectos existentes, y los que vayan a generar los proyectos propuestos; debe contar con la participación del público interesado, cualquier persona afectada o interesada, debe tener el derecho de expresar su opinión respecto a la actividad o proyecto; debe ser respetuoso de las tradiciones y cultura de los pueblos indígenas, es decir, que debe considerarse el fuerte lazo que une a los pueblos originarios con los recursos naturales, en atención a su cosmogonía y tradición, sin que se altere su modo de vida; y, por último, el contenido de cada estudio de impacto ambiental debe estar determinado y receptado mediante legislaciones y marco regulatorio.

El cuarto deber que integra las obligaciones de prevención, es el deber de establecer un plan de contingencia: significa que los Estados deben diagramar planes que permitan hacer frente a emergencias y desastres naturales, los cuales tienen que contener medidas de seguridad y protocolos de procedimiento, con el fin de mitigar los posibles daños.

Finalmente, la última y quinta obligación de prevención, es el llamado deber de mitigar los daños ambientales, en caso de que estos ya se hubieran producido: si el daño ambiental significativo, ya se produjo, pese a haberse cumplido con todas las obligaciones anteriores, esta circunstancia no exime al Estado de la obligación de tomar medidas que contribuyan a paliar y disminuir el daño ambiental. Para llevar a cabo esta tarea, los Estados deben recurrir a la tecnología y ciencia más actualizada y disponible que posean.

B) Obligación de aplicar el principio de precaución: el criterio de precaución puede ser definido como: 
«... un elemento estructural del derecho ambiental, que está dirigido a evitar los daños graves o irreversibles que pueda sufrir el medio ambiente, imponiendo medidas preventivas en aquellos eventos donde no hay certeza sobre la afectación que el desarrollo de una actividad pueda causar en los recursos naturales». (Arcila Salazar 2009, 283-304).

En efecto, la Corte IDH entiende que los Estados están obligados a aplicar el principio de precaución ${ }^{11}$, aún en los casos en que no exista certeza científica de daño ambiental, bastando para ello, la presencia fáctica de indicadores plausibles que señalen que una actividad, posiblemente, pueda acarrear daños graves e irreversibles al medioambiente.

En consecuencia, para que se configure la obligación de los Estados de ejecutar medidas eficaces con el fin de evitar el daño ambiental, deben reunirse dos elementos fundamentales: el primero es que tiene que existir una incertidumbre científica, acompañada de indicios consistentes de amenaza. La doctrina señala que estos indicadores deben ser sólidos, fundamentados en «información científica consistente, que lleve a la elaboración de una hipótesis acerca de un riesgo potencial de carácter grave o irreversible». (Andaluz Westreicher 2002, 143-147); mientras que el segundo elemento estriba en que el peligro de daño debe ser grave o irreversible, es decir, el calibre del evento dañoso debe ser capaz de afectar o modificar definitivamente un ecosistema o lesionar al derecho a la vida y a la integridad personal, toda vez que la $\mathrm{CADH}$, en su art. $29^{12}$, consagra el principio pro persona, también conocido como principio pro homine. Tal postulado puede ser definido como:

«... un criterio hermenéutico que informa todo el derecho de los derechos humanos, en virtud del cual se debe acudir a la norma más amplia, o a la interpretación más extensiva, cuando se trata de reconocer derechos protegidos e, inversamente, a la norma o a la interpretación más restringida cuando se trata de establecer restricciones permanentes al ejercicio de los

${ }^{11}$ Corte Interamericana de Derechos Humanos. Opinión Consultiva OC-23/17. Serie A, No. 23. (15 de noviembre de 2017), p. 72.

12 Artículo 29 de la Convención Americana sobre Derechos Humanos: «Ninguna disposición de la presente Convención puede ser interpretada en el sentido de: a) permitir a alguno de los Estados Partes, grupo o persona, suprimir el goce y ejercicio de los derechos y libertades reconocidos en la Convención o limitarlos en mayor medida que la prevista en ella; b) limitar el goce y ejercicio de cualquier derecho o libertad que pueda estar reconocido de acuerdo con las leyes de cualquiera de los Estados Partes o de acuerdo con otra convención en que sea parte uno de dichos Estados; c) excluir otros derechos y garantías que son inherentes al ser humano o que se derivan de la forma democrática representativa de gobierno, y d) excluir o limitar el efecto que puedan producir la Declaración Americana de Derechos y Deberes del Hombre y otros actos internacionales de la misma naturaleza». 
derechos o su suspensión extraordinaria. Este principio coincide con el rasgo fundamental del derecho de los derechos humanos, esto es, estar siempre a favor del hombre». (Pinto 1997).

En concordancia con la CADH, la Corte IDH también reconoce que, cuando se está frente a un caso concreto, en el que se confrontan derechos e interpretaciones normativas, siempre debe optarse por la solución más favorable al ser humano. Así lo ha establecido, por ejemplo, en la Opinión Consultiva OC-5/85, en la cual se refiere al principio pro homine como: «principio de interpretación extensiva de los derechos humanos y restrictiva de sus limitaciones» (Corte Interamericana de Derechos Humanos 1985, 4); y en la Opinión Consultiva OC-18/03:

«El Derecho Internacional de los Derechos Humanos, en aplicación del principio pro homine, otorga mayor prevalencia a la norma que proyecte una protección a la dignidad humana (que reconozca más ampliamente los derechos humanos), con independencia de la fuente de origen de la obligación que se trate. Por ello, el ordenamiento jurídico de un Estado tiene validez en cuanto sea congruente con los derechos humanos de las personas». (Corte Interamericana de Derechos Humanos 2003, 92).

En base a lo planteado previamente, puede deducirse que: cuando se practica una exégesis jurídica sobre un litigio en el que se controviertan extremos legales vinculados al medioambiente y, por ende, al ser humano, nunca puede soslayarse la valoración que el principio pro homine ostenta dentro del SIDH. En tal sentido, se debe propender a armonizar, mediante un correcto proceso interpretativo, a la norma internacional con la nacional, con el fin de que «frente a uno o varios textos normativos concernientes o que pueden afectar derechos humanos, se debe tomar siempre una decisión a favor de la persona» (Tenembaum y Lavalle 2010). De lo cual se concluye que el principio de interpretación pro homine, se erige como una valiosa directiva para la protección del ser humano frente a delitos y faltas que menoscaben directa o indirectamente al medioambiente. En la misma línea de pensamiento, Garrido Cordobera, ha sostenido que:

«... en esta nueva etapa del desarrollo de la temática ambiental, se impone la adopción y realización de los principios de no regresión, pro homine y de solidaridad intergeneracional, para solucionar los desafíos a los que nos enfrentaremos en los años venideros» (Garrido Cordobera 2015).

C) Obligación de cooperación interestatal: los Estados miembros de la CADH tienen la obligación de colaborar entre ellos, conforme lo estipula el art. 26 de la misma. Por ello, cuando se suscite un daño ambiental significativo de carácter transfronterizo, que pueda afectar a uno o varios Estados, es necesaria la colaboración interestatal, a efectos de prevenir y disminuir los 
efectos de cualquier tipo de degradación ambiental. Una característica de esta obligación, es que solo recae entre los Estados y no entre particulares.

En este sentido, la Corte IDH resalta la especial importancia que supone la cooperación, sobre todo, cuando se trate de recursos compartidos por varios Estados. Básicamente, la obligación de cooperación interestatal incluye tres deberes concretos: el deber de notificación; el deber de consulta y negociación; y el intercambio de información.

El primer deber implica que los Estados tienen que notificar fehacientemente a los otros, en lo que respecta a posibles daños significativos al medioambiente, que puedan derivar de actividades ejecutadas dentro de su jurisdicción y autoridad. La notificación debe ser oportuna y previa al desarrollo de la actividad.

El segundo deber alude a que los Estados deben consultarse y llevar a cabo negociaciones entre sí, de manera oportuna y de buena fe, con el fin de mitigar y prevenir los daños transfronterizos. Una importante característica de este deber es que, mientras los Estados se encuentren en etapa de consulta y negociación, la actividad de riesgo ambiental que ha motivado la obligación de cooperación debe ser paralizada hasta tanto se arribe a un acuerdo.

El tercer deber conlleva la responsabilidad de intercambiar información, en términos de conocimiento científico o tecnológico, con el objeto de facilitar la protección al ambiente, ocasionada por el daño transfronterizo.

D) Obligaciones de procedimiento: el último grupo de obligaciones que integra el principio de debida diligencia, son las obligaciones de procedimiento; así llamadas porque facilitan la implementación de políticas ambientales. En líneas generales, son tres, y consisten en: 1) asegurar el acceso a la información vinculada con posibles agravios al medioambiente: este acceso debe ser oportuno, efectivo y asequible. Además, sobre el Estado recae la obligación de entregar la información, aunque la parte que la solicita no posea un interés directo, excepto que exista una restricción legítima.

2) Garantizar la participación pública de las personas en la toma de decisiones y políticas que sean susceptibles de causar un daño al medioambiente: la participación ciudadana es relevante en materia ambiental, porque fortalece a la persona, haciendo posible que las comunidades puedan controlar el accionar de los Estados. Dicha participación se concreta mediante distintas acciones, tales como: audiencias públicas, consultas y notificaciones, procesos de revisión judicial, y mecanismos de formulación y aplicación de leyes.

3) Los Estados deben garantizar siempre el acceso a la justicia, de modo tal que las causas que versen sobre protección ambiental no son la excepción. La Corte IDH sostiene que propiciar el acceso a la justicia a los ciudadanos es elemental para la protección de todos los derechos humanos; el mismo debe asegurarse sin discriminación alguna a todos aquellos que han sido afectados por daños ambientales, es: «un medio para remediar cualquier 
violación a los derechos humanos que hubiera sido causada por el incumplimiento de normas ambientales» (Corte Interamericana de Derechos Humanos 2017, 93).

Finalmente, hay que destacar que el proceso para acceder a la justicia, debe ser efectivo y accesible.

\section{IV.LA PROTECCIÓN AMBIENTAL EN LA JURISPRUDENCIA CONTENCIOSA RECIENTE DE LA CORTE INTERAMERICANA DE DERECHOS HUMANOS}

Siendo la Corte IDH la máxima intérprete de la CADH, sobre ella recae conocer en todos los asuntos en los que se vean afectadas las garantías reconocidas en la convención (art. 33, CADH). Por lo tanto, además de su facultad consultiva, expresada a través de opiniones consultivas, la Corte IDH también detenta la capacidad de ejercer funciones contenciosas, es decir, puede dirimir en cualquier causa judicial en la que se controviertan derechos consagrados en la CADH, que han sido violados por los Estados signatarios, siempre que estos hayan reconocido su competencia.

En este orden de ideas existen, dentro de la jurisprudencia contenciosa de la Corte IDH, una serie de sentencias en las que se han analizado algunas cuestiones vinculadas a la problemática ambiental. La mayoría de ellas gravitan en torno a los pueblos originarios y la especial relación que estos guardan con el territorio y los recursos naturales, dada su cosmogonía:

«los pueblos indígenas (...) que han sobrevivido a lo largo de los años, frente a la conquista, la occidentalización, la discriminación y devastación de su hábitat, se han regido por tradiciones y costumbres compatibles y en armonía con lo que llamamos «medio ambiente»» (Calderón Gamboa 2012).

Uno de los fallos más recientes al respecto es "Caso Pueblos Kaliña y Lokono Vs. Surinam ${ }^{13}$, sentencia del 25 de noviembre de 2015. El objeto de la controversia trató sobre la falta de un marco normativo que reconozca la personalidad jurídica de los pueblos indígenas, además de la ausencia de regulación estatal en materia de derecho a la propiedad colectiva de tierras, recursos naturales y territorios de las comunidades Kaliña y Lokono, en Surinam. Aunado a lo anterior, se sumó el hecho de que el Estado concedió explotaciones mineras, y estableció reservas naturales dentro del territorio ancestral de dichos pueblos.

${ }^{13}$ Corte Interamericana de Derechos Humanos. Caso Pueblos Kaliña y Lokono Vs. Surinam. Serie C, No. 309. (25 de noviembre de 2015). Recuperado de http://www.corteidh.or.cr/docs/casos/articulos/seriec_309_esp.pdf 
La Corte IDH determinó que la inexistencia de una ley que reconozca la personería jurídica de los pueblos indígenas en Surinam, resultaba violatorio del art. $3^{14}$ de la CADH, por lo que se condenó al Estado a que reconozca la personalidad legal colectiva de los pueblos Kaliña y Lokono.

En lo atinente a materia ambiental, la Corte IDH exigió al Estado el cumplimiento riguroso de la obligación de realizar estudios de impacto ambiental, con el fin de evitar posibles daños al medioambiente por parte de mineras o de otras empresas que puedan violar el medioambiente:

«... el Estado debe garantizar que no se emitirá ninguna concesión dentro del territorio de una comunidad indígena a menos y hasta que entidades independientes y técnicamente capaces, bajo la supervisión del Estado, realicen un estudio previo de impacto social y ambiental» (Corte Interamericana de Derechos Humanos 2015, 56).

Por otro lado, en la sentencia puesta en análisis, se identifica el reconocimiento y protección de la Corte IDH al derecho a gozar de un medioambiente sano: «el Tribunal ha resaltado la importancia de la protección, preservación y mejoramiento del medio ambiente (...) como un derecho humano esencial relacionado con el derecho a la vida digna» (Corte Interamericana de Derechos Humanos 2015, 48). Otro punto a resaltar es la obligación que deben observar los Estados, relativa a asegurar el derecho a la participación ciudadana en la toma de decisiones, es decir que los Estados tienen que promover la efectiva participación pública de toda aquella población o comunidad que, eventualmente, pueda verse afectada por la realización de una actividad que implique riesgo ambiental.

La participación efectiva, según la Corte IDH, puede lograrse mediante procesos de consulta, los cuales deben ser previos al desarrollo de la actividad: «la Corte ya ha establecido que el Estado debe garantizar la participación efectiva «en relación con todo plan de desarrollo, inversión, exploración o extracción» (Corte Interamericana de Derechos Humanos 2015, 58), los cuales deben ser entendidos como: «cualquier actividad que pueda afectar la integridad de las tierras y recursos naturales» (Corte Interamericana de Derechos Humanos 2015, 48).

Otra sentencia de la Corte IDH que reviste importancia, dentro de la temática ambiental, es «Caso Pueblo Indígena Kichwa de Sarayaku Vs. Ecuador» ${ }^{15}$, sentencia del 27 de junio de 2012. Los hechos de la causa versan sobre la

${ }^{14}$ Artículo 3 de la Convención Americana sobre Derechos Humanos: «Toda persona tiene derecho al reconocimiento de su personalidad jurídica».

15 Corte Interamericana de Derechos Humanos. Caso Pueblo Indígena Kichwa de Sarayaku Vs. Ecuador. Serie C, No. 245. (27 de junio de 2012). Recuperado de http:// corteidh.or.cr/docs/casos/articulos/seriec_245_esp.pdf 
instalación de una empresa petrolífera dentro del territorio del pueblo indígena Kichwa. El Estado de Ecuador otorgó a la empresa un permiso que la habilitaba a llevar a cabo actividades de exploración y explotación petrolera.

En lo concerniente a la protección ambiental, la Corte IDH determinó la responsabilidad estatal de Ecuador, por violar las obligaciones de realizar un análisis de impacto ambiental, y por no garantizar el derecho a la consulta. En cuanto a los estudios de impacto ambiental, el tribunal sostuvo que:

«El objetivo de los mismos no es únicamente tener alguna medida objetiva del posible impacto sobre la tierra y las personas, sino también asegurar que los miembros del pueblo tengan conocimiento de los posibles riesgos, incluidos los riesgos ambientales y de salubridad» (Corte Interamericana de Derechos Humanos 2012, 64).

Respecto a la participación pública, esta debe garantizarse mediante el derecho a consulta, la cual debe efectuarse con carácter previo, es decir, debe convocarse antes de ser iniciado el proyecto o actividad; además, debe cumplir los requisitos de buena fe, al mismo tiempo que debe ser accesible, adecuada, y ser respetuosa de las costumbres y tradiciones autóctonas de los pueblos. Ello es así, porque la consulta

«... no debe agotarse en un mero trámite formal, sino que debe concebirse como «un verdadero instrumento de participación», «que debe responder al objetivo último de establecer un diálogo entre las partes basado en principios de confianza y respeto mutuos»)। (Corte Interamericana de Derechos Humanos 2012, 57).

Finalmente, la última sentencia que merece ser destacada es «Caso Claude Reyes y otros Vs. Chile» ${ }^{16}$, sentencia del 19 de septiembre de 2006. La importancia de este fallo radica en que la Corte IDH, por primera vez, condenó a un Estado por incumplir la obligación ambiental de garantizar el acceso a la información.

Los hechos que integran el objeto del litigio, se fundan en la negativa del Estado chileno, a través de su Comité de Inversiones Extranjeras, a conceder información acerca del proyecto de deforestación presentado por la empresa forestal Trillium, a los señores Marcel Claude Reyes, Sebastián Cox Urrejola y Arturo Longton - reconocidos ambientalistas-. La información solicitada por los ciudadanos tenía por fin medir el impacto que el proyecto pudiera tener sobre el medioambiente. El proyecto de deforestación provocó en la sociedad chilena una discusión pública acerca de cuál sería su impacto en el medioambiente. En virtud de ello, la Corte IDH interpretó que la

${ }^{16}$ Corte Interamericana de Derechos Humanos. Caso Claude Reyes y otros Vs. Chile. Serie C, No. 151. (19 de septiembre de 2006). Recuperado de http://www.corteidh.or.cr/ docs/casos/articulos/seriec_151_esp.pdf 
información solicitada era de interés público, toda vez que se vinculaba con un contrato de inversión extranjera, celebrado entre el Estado y dos empresas extranjeras, cuyo desarrollo podría ocasionar un daño ambiental.

El derecho que detentan los ciudadanos a tener acceso a la información que se halle bajo control del Estado, se encuentra consagrado en el art. 13.1 ${ }^{17}$ de la $\mathrm{CADH}$, como un derecho que «comprende la libertad de buscar, recibir y difundir informaciones e ideas de toda índole» (Convención Americana sobre Derechos Humanos 1969, art. 13.1). La restricción estatal al acceso a la información, perpetrada por el Estado chileno, supuso una violación al derecho de libertad de pensamiento y de expresión, contemplado en el art 13.1 de la CADH. Por ello, la Corte IDH condenó a Chile a entregar la información solicitada por las víctimas, dentro del plazo de seis meses. La Corte IDH recordó, además, en su considerando $81^{18}$, que el derecho al acceso a la información, en materia ambiental, se encuentra protegido mediante el principio 10 de la Declaración de Río, el cual dispone que: «En el plano nacional, toda persona debe tener acceso adecuado a la información sobre el medio ambiente de que dispongan las autoridades públicas» (Declaración de Río sobre el Medio Ambiente y el Desarrollo 1992, principio 10).

\section{CONCLUSIONES}

En virtud de lo expuesto en el presente trabajo, podemos extraer las siguientes conclusiones:

1. El derecho a un medioambiente sano es esencialmente un derecho humano - sin perjuicio de que resulta extensivo a toda la naturaleza en general, incluidas todas las formas de vida- Debe considerárselo un derecho en sí mismo, es decir, es autónomo, en tanto no depende de otros derechos parar ser exigible y efectivo.

Asimismo, presenta un doble alcance: a) colectivo: porque protege a las generaciones presentes y futuras; $b$ ) individual: porque presenta un interés individual, debido a que su violación supone consecuencias inmediatas para las personas. Además, posee una relación especial con otros derechos

17 Artículo 13.1 de la Convención Americana sobre Derechos Humanos: «Toda persona tiene derecho a la libertad de pensamiento y de expresión. Este derecho comprende la libertad de buscar, recibir y difundir informaciones e ideas de toda índole, sin consideración de fronteras, ya sea oralmente, por escrito o en forma impresa o artística, o por cualquier otro procedimiento de su elección».

${ }_{18}$ Considerando 81 de la Corte Interamericana de Derechos Humanos en el Caso Claude Reyes y otros Vs. Chile, sentencia del 19 de septiembre de 2006, Serie C No. 151: «En igual sentido se debe destacar lo establecido en materia de acceso a la información en la Convención de Naciones Unidas contra la Corrupción79 y en la Declaración de Río sobre el Medio Ambiente y el Desarrollo». 
humanos elementales. En este sentido, se destacan dos grupos: a) los derechos sustantivos: el derecho a la vida, el derecho a la integridad personal, el derecho a la salud, el derecho a la vivienda, el derecho al agua, el derecho a la alimentación, el derecho a la propiedad, el derecho a no ser desplazado forzadamente, y el derecho a participar de la vida cultural; b) en un segundo grupo ubicamos a los derechos de procedimiento: libertad de expresión, libertad de asociación, derecho de acceso a la información, derecho a un recurso efectivo, y derecho a la participación en la toma de decisiones.

2. Dentro del SIDH el derecho a un medioambiente sano se encuentra reconocido específicamente en el art. 11 del Protocolo de San Salvador (1988), en la OC-23/17 y, tácitamente, en el art. 26 de la CADH, por cuanto la Corte IDH lo considera incluido dentro de los derechos económicos, sociales y culturales, toda vez que los Estados están obligados a favorecer y estimular su desarrollo progresivo.

3. Ámbito de aplicación del derecho a un medioambiente sano: en el SIDH, los Estados se encuentran obligados a garantizar el derecho a un medioambiente sano, dentro o fuera de su territorio, es decir, no solo son responsables por lo que ocurra dentro de sus territorios, sino también por lo que suceda en un plano extraterritorial, siempre y cuando en ese espacio geográfico el Estado ejerza su jurisdicción o control. Por ello, los Estados pueden ser hallados culpables de ocasionar daños transfronterizos.

4. En la OC-23/17 el SIDH ha sistematizado, y consagrado expresamente, el derecho a un medioambiente sano y las correspondientes obligaciones que los Estados deben observar a los fines de cumplir con su protección, entre ellas, podemos destacar: a) el deber de debida diligencia; b) la obligación de regular las actividades que supongan un daño significativo al medioambiente; c) obligación de supervisar y fiscalizar; d) obligación de exigir, evaluar y aprobar estudios de impacto ambiental; e) obligación de disponer un plan de contingencia frente a daños y desastres ambientales; f) obligación de mitigar el daño ambiental; g) obligación de aplicar en sus políticas ambientales el principio de precaución, según el cual debe actuarse cuando hayan indicios rigurosos de posibles daños graves al medioambiente, aunque no exista una certeza científica exacta; h) obligación de cooperación entre los Estados; i) cumplir con las obligaciones de procedimiento, a saber: garantizar el acceso a la información, asegurar la participación pública en la toma de decisiones y políticas que puedan alterar o dañar al medioambiente, y garantizar el acceso a la justicia en cuestiones vinculadas a la protección ambiental.

\section{BIBLIOGRAFÍA}

Andaluz Westreicher, Carlos. 2002. «Derecho ambiental: El principio precautorio». Foro Jurídico, n. ${ }^{\circ}$ 1: 143-147. 
Arcila Salazar, Beatriz. 2009. «El principio de precaución y su aplicación judicial». Revista Facultad de Derecho y Ciencias Políticas, n. ${ }^{\circ}$ 39: 283-304.

Bermúdez Soto, Jorge. 2007. Fundamentos de Derecho Ambiental. (1 ${ }^{\mathrm{a}}$ ed.). Chile: Ediciones Universitarias de Valparaíso.

Calderón Gamboa, Jorge. 2012. Pueblos indígenas y medio ambiente en la jurisprudencia de la Corte Interamericana de Derechos Humanos: un desafio verde. San José de Costa Rica: OEA.

CÁRDENAS HERnÁNDEZ, Carlos. 2011. «Una aproximación teórica al medio ambiente sano como derecho fundamental». Derecho y Realidad, n. ${ }^{\circ}$ 9: 212-220.

Conferencia de las Naciones Unidas sobre Medio Humano. (1972). Recuperado de https://www.dipublico.org/conferencias-diplomaticas-naciones-unidas/conferencia-de-las-naciones-unidas-sobre-el-medio-humano-estocolmo-5-a-16-de-junio-de-1972/

Convención Americana sobre Derechos Humanos. (1969). Recuperado de https://www.oas.org/dil/esp/tratados_b-32_convencion_americana_sobre_derechos_humanos.htm

Corte Interamericana de Derechos Humanos. Caso Claude Reyes y otros Vs. Chile. Serie C, No. 151. (19 de septiembre de 2006). Recuperado de http://www. corteidh.or.cr/docs/casos/articulos/seriec_151_esp.pdf

— Caso Pueblo Indígena Kichwa de Sarayaku Vs. Ecuador. Serie C, No. 245. (27 de junio de 2012). Recuperado de http://corteidh.or.cr/docs/casos/articulos/seriec_245_esp.pdf

— Caso Pueblos Kaliña y Lokono Vs. Surinam. Serie C, No. 309. (25 de noviembre de 2015). Recuperado de http://www.corteidh.or.cr/docs/casos/articulos/seriec_309_esp.pdf

Opinión Consultiva OC-18/03. Serie A, No. 18. (17 de septiembre de 2003), p. 92. Recuperado de http://www.corteidh.or.cr/docs/opiniones/seriea 18 esp.pdf

Opinión Consultiva OC-23/17. Serie A, No. 23. (15 de noviembre de 2017). Recuperado de http://www.corteidh.or.cr/docs/opiniones/seriea_23_esp.pdf

— Opinión Consultiva OC-5/85. Serie A, No. 5. (13 de noviembre de 1985), Opinión separada del juez Rodolfo E. Piza Escalante, considerando 12, p. 4. Recuperado de http://www.corteidh.or.cr/docs/opiniones/seriea_05_esp.pdf

DE LuIS GARCíA, Elena. 2018. «El medio ambiente sano: la consolidación de un derecho». Iuris Tantum Revista Boliviana de Derecho, n. ${ }^{\circ}$ 13: 550-569.

Declaración Americana sobre los Derechos de los Pueblos Indígenas. (2016). Recuperado de https://www.oas.org/es/sadye/documentos/res-2888-16-es.pdf

Declaración de Río sobre el Medio Ambiente y el Desarrollo. (1992). Recuperado de http://www.un.org/spanish/esa/sustdev/agenda21/riodeclaration.htm

Dobson, Andrews. 1997. Pensamiento político verde: una nueva ideología para el siglo XXI. Traducido por José Pedro Tosaus. Barcelona: Paidós.

Estatuto de la Corte Interamericana de Derechos Humanos. (1979). Recuperado de http://www.iri.edu.ar/publicaciones_iri/manual/Ultima-Tanda/DerechosHumanos-Interamericano/11.9.\%20ESTATUTO-Corte.pdf

GARCÍA ElORRIO, Magdalena. 2011. «Algunas consideraciones en torno a la naturaleza y alcance de la noción de diligencia debida en la jurisprudencia de la Corte 
Interamericana de Derechos Humanos». Recordip Revista Electrónica Cordobesa de Derecho Internacional Público, n. ${ }^{\circ}$ 1:1-30.

GARRIDO CORDOBERA, Lidia. 2015. La aplicación de los principios de no regresión, solidaridad y "pro homine»: El desafio ambiental del siglo XXI. Buenos Aires: Editorial Astrea.

PINTO, Mónica. 1997. «El principio pro homine. Criterios de hermenéutica y pautas para la regulación de los derechos humanos». En La aplicación de los tratados de derechos humanos por los tribunales locales, editado por Abregú, Martín y Courtis, Christian, 163-171. Buenos Aires: CELS - Editores del Puerto.

Protocolo Adicional a la Convención Americana sobre Derechos Humanos en materia de Derechos Económicos, Sociales y Culturales (Protocolo de San Salvador). (1988). Recuperado de https:/www.oas.org/juridico/spanish/ tratados/a-52.html

Tenembaum, Mariela y Lavalle, Agustín. 2010. «El principio pro homine y su aplicación por los Tribunales Superiores». Ministerio Público, Defensoría de Casación. Recuperado de http://www.defensapublica.org.ar/ 


\title{
EL DERECHO A UN MEDIOAMBIENTE SANO EN EL SISTEMA INTERAMERICANO DE DERECHOS HUMANOS
}

\author{
The right to a healthy environment in the inter-american \\ human rights system
}

\author{
Isaac Marcelo Basaure Miranda \\ Abogado por la Universidad Nacional de Lomas de Zamora (Argentina) \\ Diplomado en Derechos Económicos, Sociales y Culturales por la Universidad Nacional \\ de la Patagonia San Juan Bosco
}

http://dx.doi.org/10.18543/ed-69(1)-2021pp187-209

\section{Copyright}

Estudios de Deusto es una revista de acceso abierto, lo que significa que es de libre acceso en su integridad. Se permite su lectura, la búsqueda, descarga, distribución y reutilización legal en cualquier tipo de soporte sólo para fines no comerciales, sin la previa autorización del editor o el autor, siempre que la obra original sea debidamente citada y cualquier cambio en el original esté claramente indicado

Estudios de Deusto is an Open Access journal which means that it is free for full access, reading, search, download, distribution, and lawful reuse in any medium only for non-commercial purposes, without prior permission from the Publisher or the author; provided the original work is properly cited and any changes to the original are clearly indicated. 